\title{
A review of systemic medications that may modulate the risk of glaucoma
}

\author{
Annie $\mathrm{Wu}^{1} \cdot$ Anthony P. Khawaja ${ }^{2} \cdot$ Louis R. Pasquale ${ }^{3} \cdot$ Joshua D. Stein $\mathbb{1}^{1,4,5}$
}

Received: 5 July 2019 / Accepted: 7 August 2019 / Published online: 8 October 2019

(c) The Author(s), under exclusive licence to The Royal College of Ophthalmologists 2019

\begin{abstract}
With increasing longevity, patients are developing more and more chronic diseases that require treatment with medications. Yet, it is not fully understood the extent by which these systemic medications affect ocular structures and whether they may increase or decrease the risk of sight-threatening ocular diseases. This review provides a summary of reported associations between different systemic medications and the risk of developing glaucoma or experiencing disease progression. Medication classes covered in this review that are known to or may modulate the risk of open-angle glaucoma include corticosteroids, beta blockers, calcium channel blockers, metformin, statins, selective serotonin reuptake inhibitors, bupropion, postmenopausal hormones, and cannabinoids. Medication classes addressed in this review that may increase the risk of angle closure glaucoma include anticholinergics, adrenergic agonists, certain classes of antidepressants, sulfonamides, and topiramate.
\end{abstract}

\section{Introduction}

Glaucoma is the most common cause of irreversible visual impairment worldwide and its prevalence is on the rise, with an estimated 76 million people projected to be affected worldwide in 2020 [1, 2]. Glaucoma is often a chronic condition characterized by progressive damage to the optic nerve with characteristic visual field loss [3]. Primary open angle glaucoma (POAG) is the most common type of glaucoma, accounting for more than two-thirds of all glaucoma cases [4]. Although less common that POAG, angle-closure glaucoma (ACG) is also a major cause of morbidity, especially for

$\triangle$ Joshua D. Stein

jdstein@med.umich.edu

1 Department of Ophthalmology and Visual Sciences, University of Michigan Medical School, Ann Arbor, MI, USA

2 NIHR Biomedical Research Centre, Moorfields Eye Hospital NHS Foundation Trust and UCL Institute of Ophthalmology, London, UK

3 Department of Ophthalmology, Icahn School of Medicine at Mount Sinai, New York, NY, USA

4 Center for Eye Policy and Innovation, University of Michigan, Ann Arbor, MI, USA

5 Department of Health Management and Policy, University of Michigan School of Public Health, Ann Arbor, MI, USA persons residing in Asian countries [2]. Elevated intraocular pressure (IOP) is the only known modifiable risk factor for glaucoma, yet some patients still experience progressive vision loss despite maintaining low IOPs, suggesting there must be other factors besides IOP that alter the course of this disease.

Several classes of systemic medications are known to or suspected to modulate glaucoma risk, either through their direct effects on IOP or via mechanisms independent of IOP (Table 1). Polypharmacy, characterized by use of $\geq 5$ prescription medications at one time, has become increasingly prevalent. Nearly two-thirds of all US adults aged 40-64 and $90 \%$ of individuals $\geq 65$ years of age have been prescribed 5 or more medications at a time [5, 6]. The rise of polypharmacy coupled with the increasing burden of glaucoma highlight the need for a better understanding of how systemic medications affect glaucoma risk. This review summarizes the literature on associations between common classes of systemic medications, IOP, and risk for POAG or ACG.

\section{Systemic medications known to increase risk of open-angle glaucoma}

\section{Corticosteroids}

Ocular hypertension secondary to corticosteroid use has been well established and can lead to secondary open-angle 
Table 1 Summary of systemic medications that may increase or decrease the risk of glaucoma

Open-angle glaucoma

Medications known to increase the risk of OAG

Corticosteroids
Medications known to decrease the risk of OAG

Beta blockers
Medications that may decrease the risk of OAG

Metformin

Statins

Bupropion (TNF-alpha antagonists)

SSRIs

Post-menopausal hormones

Cannabinoids
Medications with mixed findings

Calcium channel blockers

Angle-closure glaucoma

Medications known to increase the risk of AACC

Anticholinergics

Adrenergics

Cholinergics

Sulfonamides

Anticoagulants

$O A G$ open-angle glaucoma, $A A C C$ acute angle-closure crisis, TNF tumor necrosis factor, SSRIs selective serotonin reuptake inhibitors

glaucoma (OAG) in susceptible individuals [7-10]. Studies have demonstrated that exposure to corticosteroids causes increased resistance of aqueous outflow through the trabecular meshwork. This may be attributed to accumulation of undigestible glycosaminoglycans in the human trabecular meshwork $[9,11]$ as a result of inhibition of matrix metalloproteinase inhibitors $[10,12]$ or through upstream activation of transforming growth factor $\beta$ signaling [13].

Steroid-induced ocular hypertension (SIOH) has been linked to a range of drug delivery routes including oral or intravenous, inhaled or intranasal, topical eye drops, topical cutaneous ointments, periocular injection, and intraocular corticosteroids [8, 14-17]. Approximately one quarter to one third of patients develop elevated IOP from corticosteroid use, with 5\% classified as "high responders" defined as an IOP increase $>15 \mathrm{mmHg}$ and IOP measurements $>31$ $\mathrm{mmHg}$ [18-21]. Patients with a known history of glaucoma or a positive family history of glaucoma have a greater risk of IOP elevation from corticosteroid use [21]. Both acute and chronic IOP elevation can occur with corticosteroid use, and time of onset varies with the dosage and potency of the corticosteroid. For example, studies have reported IOP elevations within 3-6 weeks of initiation of topical corticosteroid eye drop therapy $[19,22]$.

Fortunately, SIOH usually resolves within 2-4 weeks of discontinuing the corticosteroid, although normalization of IOP may take longer with chronic corticosteroid use [23]. Replacement of corticosteroids with steroid-sparing agents such as nonsteroidal anti-inflammatory agents can be very helpful in controlling the underlying inflammatory process for which the corticosteroids had been prescribed while also limiting the risk of glaucoma [24]. If discontinuation of corticosteroids is not possible, a lower dose or a lower potency corticosteroid may be used. For cases of persistent IOP elevation from corticosteroids, glaucoma medications may be prescribed. Occasionally surgical interventions are needed to stabilize IOP. Surgical options including laser trabeculoplasty, trabeculotomy, canaloplasty, trabeculectomy, or glaucoma drainage device implantation [25-27]. Minimally invasive glaucoma surgery has also been reported to successfully reduce IOP in SIOH; a case report of a pediatric patient with uveitis requiring intravitreal and subconjunctival corticosteroids who developed $\mathrm{SIOH}$ experienced IOP lowering in both eyes following bilateral sequential placement of XEN gel stents [28].

Given the wide range of systemic medical conditions for which corticosteroids are prescribed, a considerable number of patients may be unknowingly exposed to the ocular side effects of corticosteroids. The prevalence of corticosteroid use in the general population has been estimated to be as high as 7\% [29]. Communication between health care providers in managing these patients is key; medical professionals who routinely prescribe corticosteroids should seek consultation with eye care professionals to monitor for IOP elevation especially in cases of anticipated prolonged usage or potent corticosteroid dosing and patients who are known to have glaucoma or a family history of this condition.

\section{Medications known to decrease the risk of open-angle glaucoma}

\section{Beta blockers}

Beta blockers are a class of medications commonly used for their antiarrhythmic and antihypertensive properties; 
selective beta-blockers for the beta-1 receptor are known as cardioselective beta blockers while nonselective beta blockers that target beta- 1 and beta- 2 receptors are considered to have greater antihypertensive effects. A seminal case series by Phillips et al. in 1967 was the first to report IOP reduction from systemic beta blocker use [30]. In fact, this study and subsequent others led to the development of topical beta blocker eye drops for use in glaucoma treatment. Many studies have shown that systemic beta blocker use is associated with IOP reduction [31-34]. Nonselective beta blockers are thought to be more effective in lowering IOP compared with cardioselective agents given increased activity at beta- 2 receptors $[31,35]$. In a large populationbased study conducted in the United Kingdom, patients receiving oral beta blockers were found to have $\sim 1 \mathrm{mmHg}$ lower IOP compared with those not using these medications after controlling for age, sex, and body mass index [34]. Additional evidence suggests that oral beta blockers may be associated with a decreased risk of incident glaucoma [36].

Patients already taking oral beta blockers may not achieve as significant reductions in IOP with the addition of a topical beta blocker. Furthermore, patients taking oral and topical beta blockers concurrently may be at increased risk for the adverse effects from concomitant usage of both of these medications [37, 38]. Alternate classes of topical glaucoma medications should be considered in such cases; brimonidine, an alpha-2 agonist, has been found to not only be free of cardiovascular side effects but also more effective at lowering IOP than timolol, a topical beta blocker, in patients concurrently taking systemic beta blockers [37].

\section{Medications that may decrease the risk of open-angle glaucoma}

\section{Metformin}

Metformin, a synthetic biguanide, is one of the most frequently prescribed treatments for type 2 diabetes. Metfor$\min$ is a caloric-restriction-mimetic drug whose geroprotective effects have been shown to delay or reduce risks for a variety of age-associated systemic diseases; recent studies have demonstrated an association between metformin use and decreased risk of OAG in persons with diabetes mellitus [39, 40]. A large retrospective cohort study by Lin et al. found that among patients aged 40 years or older with diabetes mellitus and no preexisting record of $\mathrm{OAG}$, those prescribed the highest quartile of metformin hydrochloride had a $25 \%$ reduced OAG risk compared with those who took no metformin. In that study, patients taking a standard dose of $2 \mathrm{~g}$ of metformin per day for 2 years were predicted to have a $21 \%$ reduction in the risk of developing OAG [39]. Metformin's protective effects may stem from its beneficial effects on glycaemic control and improved vascular health; however, in Lin's study among multiple hypoglycaemic medications tested (metformin, sulfonylureas, thiazolidinediones, meglitinides, and insulin), metformin was the only agent that demonstrated a protective effect against $\mathrm{OAG}$, suggesting that the mechanism limiting the risk of OAG may go beyond simply improved glycaemic control [39]. Furthermore, in their study, OAG risk reduction from metformin persisted even after controlling for glycated hemoglobin (HbA1c) levels, again supporting the notion that other mechanisms beside glycaemic control such as those involving neurogenesis, inflammatory systems, or longevity pathways may be responsible for the reduction in risk of OAG [39, 41].

Not all studies have found metformin to be protective against OAG development or disease progression. A retrospective study by Wang et al. examining patients with preexisting OAG failed to demonstrate that metformin use could reduce the risk of progression [42]. Differences in study design may, in part, explain discordances between this study and the study by Lin. Wang's group used receipt of filtration surgery as a proxy for progression of OAG; yet since many patients who experience $\mathrm{OAG}$ progression are treated with other interventions, such as additional glaucoma medications or laser trabeculoplasty prior to undergoing filtration surgery, it is unclear how omitting those interventions from the analyses affected the results of that study. In addition, clinical practice varies among glaucoma specialists and the decision to perform filtration surgery may occur at different stages of the disease and for different reasons, not all of which are related to disease progression. In summary, while there is some support that metformin may be beneficial in reducing the risk of OAG, additional studies are warranted before clinicians should begin prescribing this medication as a prevention or treatment of OAG.

\section{Statins}

Statins are a class of medications used to treat hyperlipidaemia; they function by competitively inhibiting HMGCoA reductase, the rate-limiting enzyme of the cholesterol biosynthetic pathway. In light of evidence showing a protective effect against cerebrovascular disease, interest in a neuroprotective role for statins in glaucoma has grown in recent years [43-45]. Statins have been associated with decreased risk for developing OAG while other cholesterollowering agents have not, suggesting properties unique to statins (beyond lowering of cholesterol) may be responsible for such a risk reduction [46]. One proposed mechanism involves upregulation of endothelial nitric oxide synthase (eNOS); the subsequent increase in nitric oxide causes vasodilation and increased retinal and choroidal blood flow, 
potentially improving preservation of the optic nerve and retinal nerve fiber layer [47]. Statins may achieve this through inhibition of Rho and Rho-kinase activity, which consequently leads to upregulation of eNOS expression [47, 48]. In addition, inhibition of Rho-kinase has been shown to increase outflow facility through the trabecular meshwork, resulting in lowering of IOP, a known risk factor for glaucoma [49]. Finally, statins may exert a neuroprotective effect by decreasing glutamate-mediated cytotoxicity and protecting against apoptosis within the central nervous system [43, 50].

There is also mounting evidence in the clinical literature that statins decrease OAG risk and/or mitigate disease progression. Among the population-based studies and retrospective case series in the literature on this topic, five have shown decreased OAG risk, [46, 51-54] two have shown decreased functional damage from glaucoma as captured on perimetry [55, 56], and one has shown decreased structural damage to the retinal nerve fiber layer with statin use (Table 2) [57]. A large retrospective cohort analysis using data on more than 500,000 patients with hyperlipidaemia enrolled in a U.S. managed care network found that the risk of developing OAG decreased $0.3 \%$ for every additional month of statin consumption, and patients who took statins continuously for 2 years had an $8 \%$ decreased risk of OAG relative to those with hyperlipidaemia who received no statin therapy [52]. The study also found that every additional month of statin exposure decreased the hazard of progressing from a diagnosis of glaucoma suspect to OAG by $0.4 \%$, and decreased the hazard of requiring medications for OAG by $0.4 \%$ [52]. Talwar et al. found that among 25,420 commerciallyinsured patients with hyperlipidaemia who were receiving statins, those who filled prescriptions continuously for 2 years had a $21 \%$ reduced risk of glaucoma compared with nonusers even after accounting for baseline low-density lipoprotein level, and that there was no significant difference in protective effect between daily dosage of statin $(40 \mathrm{mg}$ vs. $80 \mathrm{mg}$ ) or type of statin (atorvastatin, lovastatin, cerivastatin, rosuvastatin, fluvastatin, pravastatin, or simvastatin) [51]. Kang et al. showed that among 136,782 adults aged 40 years or older, 5 or more years of statin use was associated with a $21 \%$ lower risk of POAG and that 10 or more years of use was associated with a $40 \%$ lower risk of POAG compared with patients who never took statins [54]. A prospective study demonstrated that statin use was correlated with stabilization of visual field findings over 3 years among patients with normal tension glaucoma [56]. Similarly, statin use has been found to curtail glaucomatous changes to the optic nerve and nerve fiber layer on confocal scanning laser ophthalmoscopy [57].

By contrast, a study from Taiwan reported high dose statins actually increased the risk of OAG [58], and another found a modest association between statin use and IOP elevation [59], and three others found no significant effect of statins on IOP or use of adjunctive IOP lowering therapies (Table 2) [34, 53, 60]. For example, in a retrospective review of health care claims data from Canada, Iskedjian and colleagues found no significant association between statin use and reduction of adjunctive IOPlowering therapies among 8548 patients taking prostaglandin analogs for OAG [60]. In addition, the European Prospective Investigation into Cancer-Norfolk Eye Study (EPIC-Norfolk Eye Study) reported that the observed associations between statin use and IOP reduction were no longer significant after adjustment for concomitant systemic beta-blocker use; the investigators hypothesized that IOP reduction among patients using both medications may have been driven predominantly by beta-blocker use and not use of statins [34].

There is an increasing prevalence of metabolic syndrome, a condition characterized by hyperlipidaemia, systemic hypertension, obesity, and elevated fasting blood glucose [61]. Patients with this condition often require several different systemic medications to address each component of this syndrome. Since several of the underlying components of metabolic syndrome may themselves affect the risk of glaucoma, as may some of the medications used to treat these diseases, it can be challenging for researchers to sufficiently account for confounding, permitting one to isolate the beneficial or detrimental effects of some of these agents on the risk of OAG [62]. As such, while evidence in the literature supporting the notion that statins may reduce the risk of OAG or disease progression, a large prospective multicentre randomized controlled trial is needed to definitively answer the question regarding whether a causal relationship exists between statin use and reduction of OAG risk.

\section{Selective serotonin reuptake inhibitors}

Selective serotonin reuptake inhibitors (SSRIs) are used as first line agents in the treatment of depression and other psychiatric conditions, and there is also some suggestion that these medications may reduce the risk of OAG. A large retrospective analysis by Zheng et al. found that of all the various systemic drug classes they studied, SSRIs were most strongly associated with a reduction in the need for laser or incisional glaucoma surgery among patients with underlying OAG [63]. Their study found that SSRI users had a 30\% reduced risk of POAG requiring filtration surgery compared with non-users, an association that was independent of the underlying reason for taking these medications. Serotonin and norepinephrine reuptake inhibitors (SNRIs) were also associated with an $\sim 30 \%$ reduced risk of POAG requiring filtration surgery though less statistically significantly than SSRIs, 


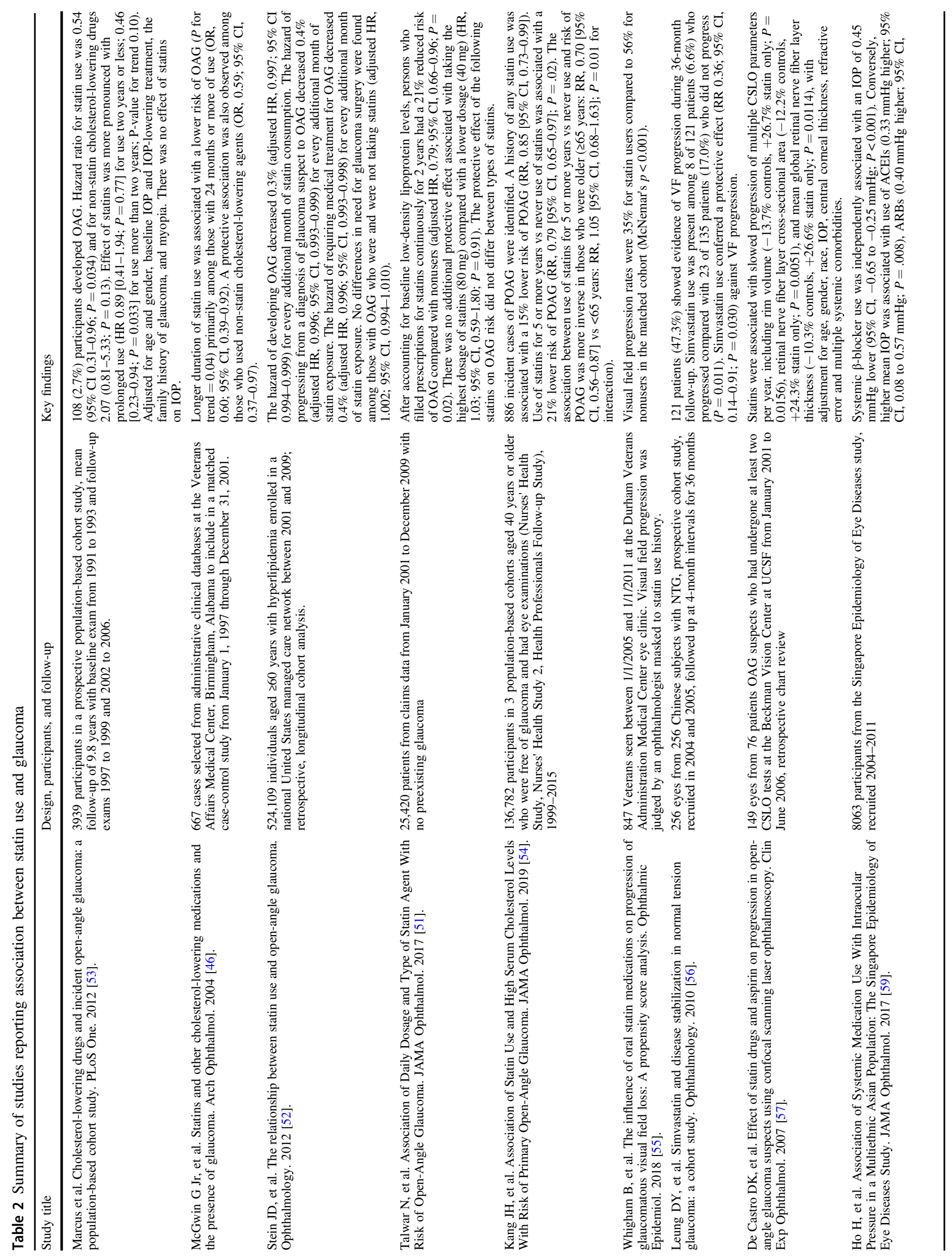


and the reduction in risk was not seen at all with tricyclic antidepressants [63]. Serotonin receptors are present in retinal ganglion cells, and some evidence suggests that they may directly modulate IOP [64]. This may explain how these medications may reduce the risk of $\mathrm{OAG}$ or disease progression.

Other studies have found no association between SSRIs and OAG [42, 65]. A large retrospective study by Stein et al. using health care claims data examined several classes of antidepressants and found no association between SSRI use and OAG [65]. Such discrepancies can potentially be explained by differences in study design, given that the former was focused specifically on POAG while the latter considered all forms of OAG; in addition, Zheng's study used receipt of laser or incisional glaucoma surgery to qualify a patient as experiencing disease progression which may have resulted in exclusion of cases of progression that were managed medically. The possibility that the findings from the study by Zheng's group were borne out of chance alone seems unlikely, as Zheng's group also found a significant dose-response relationship between SSRI use and glaucoma risk such that greater use of these medications resulted in greater risk reduction. Furthermore, the argument that prescribers may be avoiding SSRI use among patients with underlying glaucoma due to concern for inducing acute angle closure crisis (AACC) (from mydriasis-induced pupillary block due to weak anticholinergic effects) would not be consistent with this dose-response finding. In light of these discordant findings, further work is needed to better understand the relationship between SSRIs and glaucoma.

\section{Bupropion}

Bupropion is an antidepressant that functions by selectively inhibiting dopamine and noradrenaline reuptake. A few studies have connected bupropion use with a reduced risk of OAG. A retrospective review of health care claims data for a large managed care network showed that among patients $\geq 35$ years old with newly-diagnosed OAG, each additional month of bupropion use was associated with a $0.6 \%$ reduction in risk of developing OAG compared with persons with no use, and the association did not differ among patients taking the medication for depression or for other purposes like smoking cessation [65]. A large crosssectional study using self-reported survey data found that patients who reported bupropion use for more than 1 year had $\sim 90 \%$ decreased odds of getting diagnosed with glaucoma compared with those not using bupropion or using it for less than 1 year duration [66]. Zheng et al. found that bupropion use was associated with a reduced risk of POAG in their retrospective review of claims data, although this fell short of statistical significance after taking into 
account the large number of prescription drugs they evaluated [63].

Tumor Necrosis Factor (TNF) is a known mediator of retinal ganglion cell death in glaucoma; studies have shown that bupropion lowers the level of TNF- $\alpha$ [67]. Anti-TNF drugs have been shown to be neuroprotective in animal models; etanercept is a TNF- $\alpha$ antagonist that has been found in rat models to inhibit the inflammatory response mediated by microglial cells, preventing axonal degeneration and subsequent loss of retinal ganglion cells [68]. Additional basic science and clinical studies would be useful to substantiate whether bupropion or other medications that inhibit TNF- $\alpha$ may play a role in reducing the risk of OAG or disease progression.

\section{Postmenopausal hormones}

There is evidence that sex hormones may play a role in glaucoma pathogenesis. Endogenous estrogen has been found in population-based studies to be protective against OAG; several other studies have found that postmenopausal hormones $(\mathrm{PMH})$, which usually consist of oral preparations containing estrogen, estrogen and progesterone, or estrogen along with an androgen, can decrease IOP or OAG risk (Tables 3a and 3b) [69-87]. Estrogen receptors are present in RGCs; estrogen has been found to decrease IOP and provide a protective effect on RGCs in a rat model of retinal ischemia [88].

Studies have quantified lifetime estrogen exposure (which can be affected by age of menarche, age of menopause, oral contraceptive use, and history of oophorectomy) and assessed whether such exposure affected the risk of OAG. In the Rotterdam Study, a study monitoring more than 3000 women for ocular diseases, those who went through menopause before 45 years of age had a higher OAG risk compared to the reference group who went through menopause at an older age [70]. The Blue Mountains Eye Study examined 2072 women ages 49-97 years and found significantly increased OAG risk with later $(>13$ years old) compared with earlier ( $\leq 12$ years old) age of menarche. This study also found an increased risk of OAG associated with increasing parity, though timing of menopause had no significant association with OAG risk [69]. Using data from the Nurses' Health Study spanning from 1980 to 2002 , among the 66,417 women prospectively studied, late menopause (entering menopause at age $\geq 54$ years vs. age 50-54) was associated with reduced risk of POAG, and use of estrogen with progestin was associated with a reduced risk of high tension OAG [77]. NewmanCasey and colleagues conducted a retrospective longitudinal cohort analysis of $>150,000$ enrolees in a U.S. managedcare plan and found that among women aged $\geq 50$ years old, each additional month of taking PMH preparations containing estrogen was associated with a $0.4 \%$ reduced risk for POAG after adjustment for confounding factors [71]. Using data from the Women's Health Initiative, a posthoc analysis revealed that postmenopausal women aged $\geq 65$ years old with a history of hysterectomy who were randomized to receive estrogen-alone treatment had significantly lower IOP than women randomized to receive placebo 5 years after initiation of estrogen treatment, while treatment with estrogen plus progestin had no effect on IOP [75]. This study was the first and largest using data from a randomized, double-masked, placebo-controlled trial to find a significant, albeit modest effect of estrogen treatment on IOP $(\sim 0.5 \mathrm{mmHg})$, an important risk factor for OAG.

\section{Cannabinoids}

Cannabinoids are a class of drugs that act on cannabinoid receptors and alter neurotransmitter release in the central nervous system; cannabinoid type-1 receptors have been found in the ciliary epithelium, trabecular meshwork, and Schlemm's canal [89]. A number of case reports and in vitro studies have found that cannabinoids can effectively lower IOP [90, 91]. Immunofluorescence studies show that cannabinoids bind to receptors in rat, bovine, and human ciliary epithelial and trabecular meshwork cells, suggesting that cannabinoids may be involved in increasing aqueous humor outflow or by reducing aqueous production [92]. However, substantial and frequent doses of cannabinoids are required to achieve sustained IOP reduction, and this can predispose patients to cardiovascular and neurologic adverse effects [91]. Given their short duration of action and multiple psychotropic and cardiovascular adverse effects along with a lack of evidence supporting an effect on altering the disease course of glaucoma, cannabinoids are generally not recommended for use in glaucoma treatment, and multiple professional societies including the American Academy of Ophthalmology, the American Glaucoma Society, and the Canadian Ophthalmological Society have put forth statements recommending against the use of cannabinoids for management of glaucoma [93, 94]. In an age of increased marijuana legalization, eye care professionals should be cognizant of the limited effectiveness of cannabinoids as a treatment for glaucoma as well as the adverse effects of these agents. More research is needed to try to identify novel ways to administer cannabinoids to attain the beneficial IOP-lowering effects with fewer adverse effects, or to develop novel compounds that effectively lower IOP for lengthier periods of time.

\section{Calcium channel blockers}

Calcium channel blockers oppose the action of calcium channels located on vascular smooth muscle, 


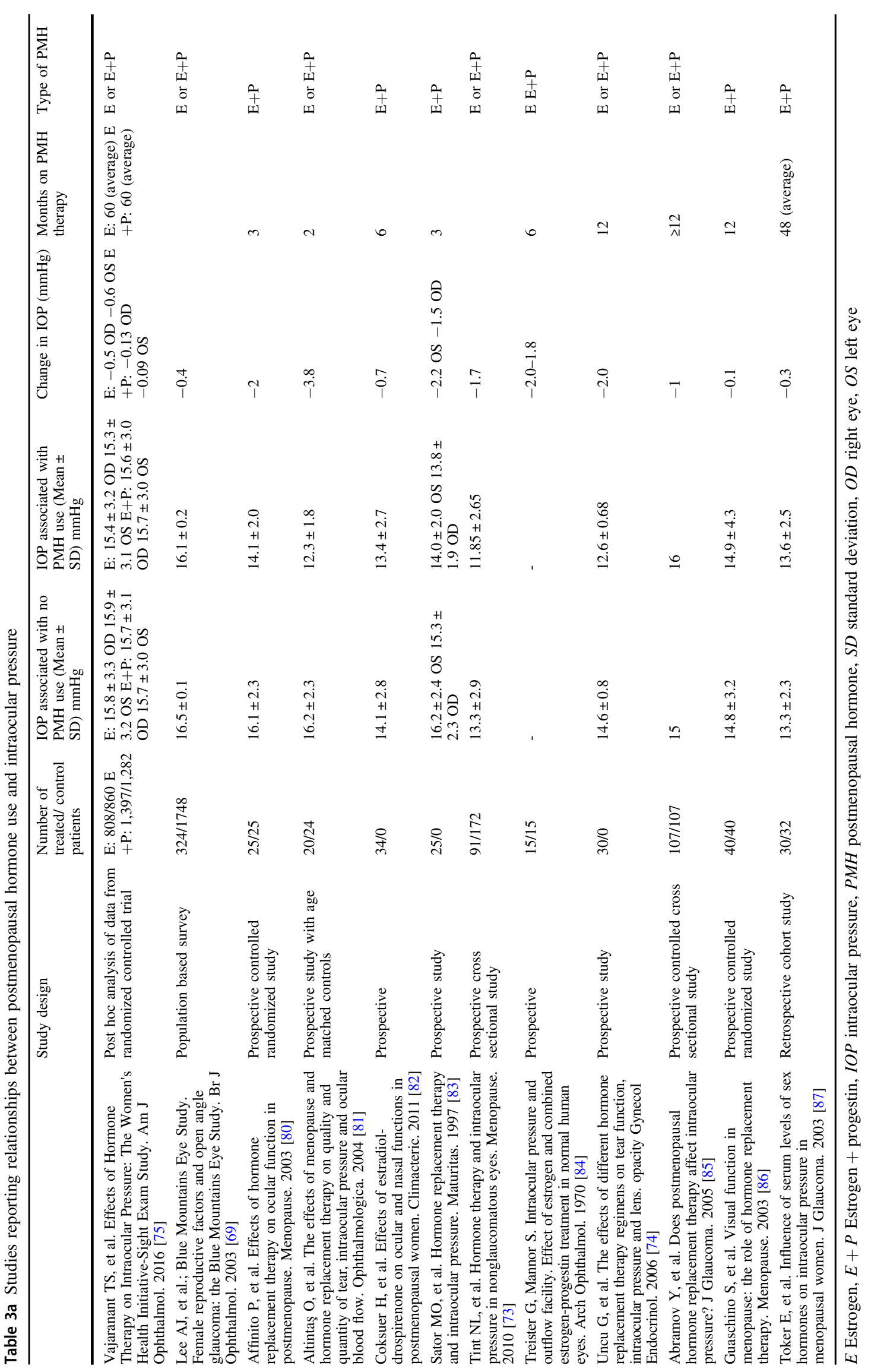




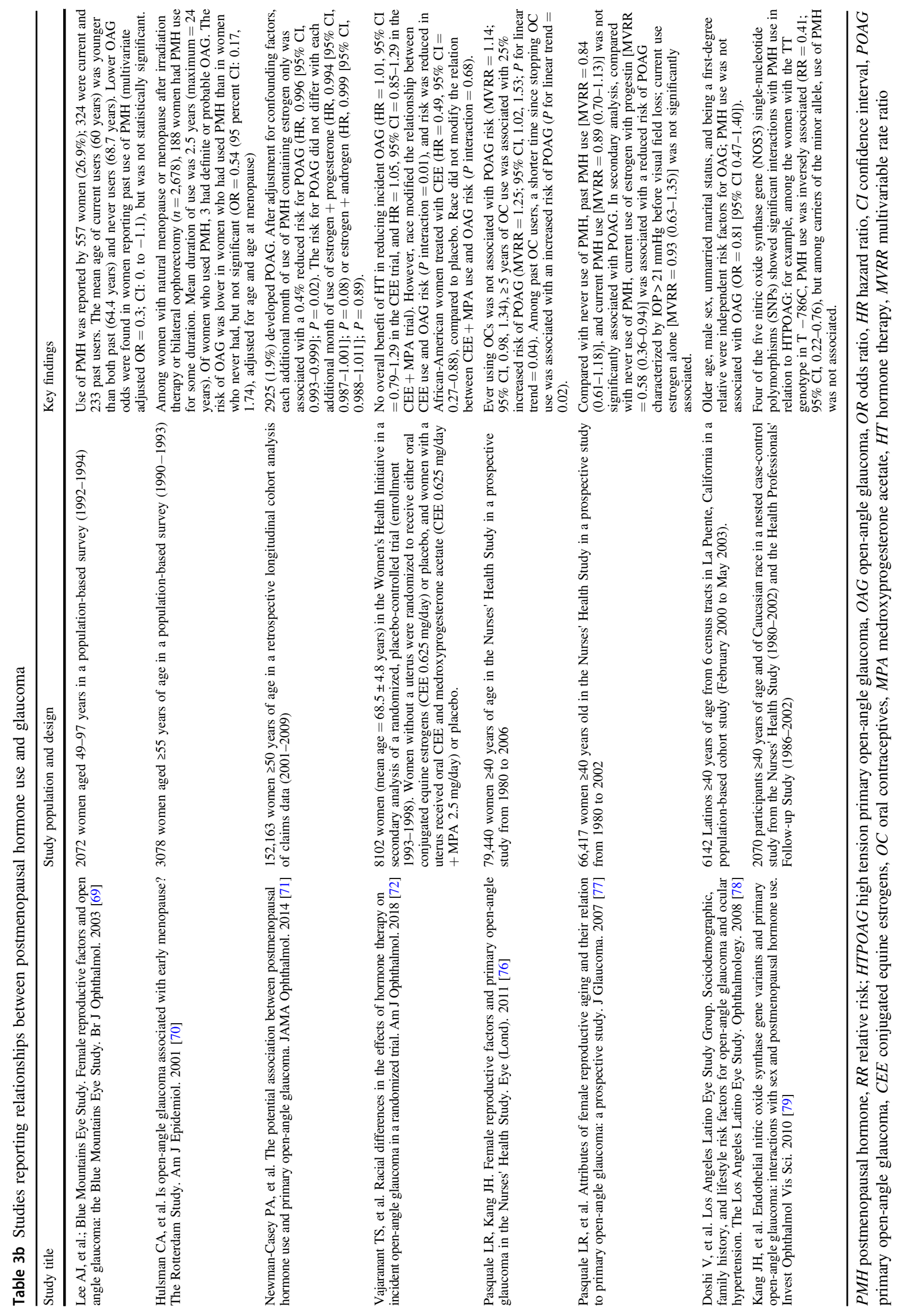


myocardium, and adrenal cortex cells, leading to decreased heart rate and decreased systemic blood pressure. Contradictory findings have been reported with respect to calcium channel blocker use, IOP, and risk of OAG. Some studies have suggested that calcium channel blockers can increase optic nerve head and choroidal blood flow, and potentially retard visual field deterioration in patients with OAG [95-98]. In vitro studies suggest that calcium channel blockade reduces extracellular matrix gene response in lamina cribosa cells induced by mechanical strain [99]. Others have proposed that venous dilation by calcium channel blockers can increase perfusion to the optic nerve head $[95,100]$.

However, other studies have found that calcium channel blocker use is actually associated with increased risk of OAG [36, 42, 63]. Zheng et al. found that patients who underwent filtration surgery for POAG were $26 \%$ more likely to have had calcium channel blocker exposure within the previous 5 years compared to matched controls with no record of POAG who underwent cataract surgery. These investigators found that this effect was primarily driven by amlodipine, which was the most commonly prescribed calcium channel blocker in their study [63]. The same associations were not found in other classes of antihypertensives; there was no significant association between angiotensin-converting-enzyme (ACE) inhibitors and POAG despite it being the most commonly prescribed antihypertensive drug in the study [63]. In a large prospective population-based cohort study, Muskens et al. found a 1.8-fold higher risk of developing OAG among patients exposed to calcium channel blockers, compared with those without exposure to calcium channel blockers [36]. In a separate study using two large administrative health care claims databases, Wang et al. also found an association between calcium channel blockers and OAG progression, defined as undergoing filtration surgery [42]. Notably, Wang et al. analyzed multiple drugs including angiotensin-II receptor blockers, metformin, SSRIs, fibric-acid derivatives, and calcium channel blockers, with only calcium channel blockers being found to have a significant association with $\mathrm{OAG}$ progression [42].

Calcium channel blockers are generally not first or second line treatments for hypertension. As such, they may be more often used in patients with refractory hypertension [101], which is itself a known risk factor for OAG. Unfortunately, retrospective studies such as those cited above, are limited in their ability to control for and quantify duration and severity of comorbidities such as hypertension that may, in and of themselves, affect the risk of OAG. A prospective randomized controlled trial would help better elucidate whether calcium channel blockers adversely affect the risk of developing OAG.

\section{Systemic medications known to increase the} risk of angle closure glaucoma

\section{Sulfonamides}

Sulfonamide-induced angle closure glaucoma was first described in 1962; since that time, a variety of sulfacontaining and sulfa-derived drugs including antibiotics (sulfamethoxazole, flucloxacillin), diuretics (hydrochlorothiazide, chlorthalidone, indapamide, furosemide), anti-inflammatory agents (sulfasalazine), and anti-epileptics (topiramate, zonisamide) have been reported to precipitate AACC [102-120]. One proposed mechanism for sulfonamide-induced angle closure is that an osmotic disturbance within the crystalline lens leads to hydration of the lens and subsequent thickening with anterior displacement of the lens-iris diaphragm [121]. Another proposed pathophysiological mechanism is that sulfonamides can induce ciliary body edema with subsequent supraciliary effusion, which causes forward rotation of the ciliary body and mechanical angle closure [122].

Topiramate is a sulfamate-substituted monosaccharide antiseizure medication that is also used to treat neuropathic pain, depression, and migraine. More than 128 cases of AACC associated with topiramate use have been reported in the literature. Topiramate-induced angle closure glaucoma typically presents bilaterally [123]. In one large case-control study, the risk of angle closure was five times higher among patients younger than 50 years of age who were taking topiramate compared with nonusers [123]. Topiramate causes angle closure primarily by precipitating supraciliary effusions with forward rotation of the iris lens diaphragm; ultrasound biomicroscopy of eyes with topiramate-induced angle closure show only minimal contribution to anterior chamber narrowing from increased lens thickness, although the latter phenomenon contributes to induced myopia that accompanies the angle closure glaucoma attack [122]. Blurred vision is the most common presenting symptom, and patients typically present with symptoms within the first 2 weeks of initiating use, although a small percentage of patients have been found to develop increased IOP within hours of doubling the dose of topiramate [124]. Myopia up to 8.75 diopters can be induced, and can take weeks to resolve after discontinuation of the medication [124]. Supraciliary effusions can be confirmed on ultrasonography; high-frequency ultrasound can be used to evaluate for forward rotation of the ciliary processes and angle closure in ambiguous cases.

Acetazolamide and methazolamide have been implicated in cases of AACC [113, 114, 116, 117, 125]. Both drugs are sulfonamide-derived carbonic anhydrase inhibitors, commonly used as diuretics and in the treatment of intracranial hypertension and to abruptly lower IOP in cases of acute 
glaucoma. Methazolamide is metabolized by the liver while acetazolamide is renally excreted; the former has a longer half-life and decreased risk of metabolic acidosis. Sulfonamide-induced angle closure has not been reported with use of topical carbonic anhydrase inhibitors.

IOP usually quickly normalizes with discontinuation of the offending agent. In addition, topical IOP-lowering agents can be used in the acute phase. Although oral acetazolamide is generally used in the acute setting to treat elevated IOP, in the case of sulfonamide-induced angle closure, it should be avoided given potential cross-reactivity and exacerbation of the underlying process. In addition, topical miotic agents such as pilocarpine can lead to further anteriorization of the lensiris diaphragm and should be avoided in these cases [124]. Uveal effusions from sulfonamides are thought to have an underlying inflammatory mechanism; thus, anti-inflammatory treatment with oral or intravenous corticosteroids can be effective. Laser iridotomy is not helpful as the angle closure is not precipitated by pupillary block. In cases refractory to medical therapy, ciliochoroidal effusion drainage has been reported to successfully restore anterior chamber depth and normalize IOP [126]. Infrequently, lensectomy, pars plana vitrectomy, or incisional glaucoma surgery may be required.

\section{Anticholinergics}

Anticholinergic mydriasis occurs through blockade of parasympathetic muscarinic acetylcholine receptors on the iris sphincter muscle and can lead to pupillary block in susceptible eyes. Commonly used topical cycloplegics such as tropicamide and scopolamine can directly precipitate AACC in individuals with narrow angles; these patients may safely undergo cycloplegia after being treated with laser iridotomy [127, 128]. In a large cross-sectional population-based survey, Patel et al. identified presence of a shallow anterior chamber on penlight examination, history of glaucoma, and blindness as three screening criteria that if used appropriately, rendered the risk of dilating a potentially occludable angle to less than 1 in 333 [127].

Oral and intravenous anticholinergic therapy have been reported to cause AACC in rare cases. Oxybutynin, an inhibitor of muscarinic receptors on detrusor smooth muscle fibers in the bladder used to treat urinary urge incontinence, has been reported in rare case reports to cause AACC [129, 130]. Over-the-counter herbal remedies may contain substances with anticholinergic properties such as belladonna, which has been reported to cause bilateral angle closure [131]. Iatrogenic angle closure from commonly used anticholinergic anesthetic or adjunctive anesthetic agents (muscle relaxants, atropine, and scopolamine) has also been reported [132-134].

Inhaled anticholinergics used to treat pulmonary disease such as tiotropium and ipratropium have been reported rarely to precipitate AACC [135-137]. These cases can result from both systemic absorption of the medication and inadvertent topical ophthalmic absorption through conjunctival and corneal exposure, which can occur with illfitting face masks; such cases can present unilaterally. Knowledge of this potential adverse effect and avoidance of directing nebulizers and inhalers toward the eyes can reduce the risk of AACC from these medications.

Botulinum toxin causes transient muscle paresis by inhibiting the release of acetylcholine at the skeletal muscle neuromuscular junction and can cause pupillary dilation when injected near the eye. Botulinum toxin has been reported to cause AACC when injected in the periocular region to treat blepharospasm or for cosmetic purposes $[138,139]$. Patients electing to undergo botulinum injections should be counseled to seek care if they develop any of the typical symptoms characteristic of AACC such as nausea, blurred vision, headache, ocular pain, or mydriasis, which my last several weeks following injection [139]. Atrisk patients should be evaluated by gonioscopy and undergo laser iridotomy if indicated for prophylaxis prior to receiving botulinum injections.

\section{Antidepressants and other drugs altering serotonin, dopamine, and norepinephrine metabolism}

SSRIs, SNRIs, tricyclic antidepressants, and other drugs involved in serotonin, dopamine, and norepinephrine metabolism have been reported in case reports to rarely trigger AACC after short or long-term exposure, though precise mechanisms are unclear [118, 140-149]. One proposed pathophysiological mechanism is that antidepressant drugs can act as weak anticholinergic agents to cause angle closure through mydriasis and pupillary block; additionally, pupil dilatation mediated by 5-HT (5-hydroxytryptamine, serotonin) receptors and norepinephrine receptors can result from increased levels of serotonin and norepinephrine caused by SSRI or SNRI use [64]. Other reports have found uveal effusions to be present in patients presenting with AACC from SSRI and SNRI use, and propose a mechanism similar to that of topiramate $[142,145,147]$. Murphy et al. reported probable associations between bilateral AACC and multiple drugs involved in serotonin, dopamine, and norepinephrine metabolism, including escitalopram (a SSRI), venlafaxine (a SNRI), bupropion (a norepinephrine and dopamine-reuptake inhibitor), cabergoline (a dopamine receptor agonist), and ecstasy (a releasing agent of serotonin, norepinephrine, and dopamine) [118]. Serotonin receptors are present in the ciliary body and choroid; alteration of serotonin metabolism from drug exposure is one proposed mechanism by which these medications may promote uveal effusion and bilateral AACC [147, 150152]. Dopamine receptors are similarly present in the ciliary 
body; higher levels of dopamine in aqueous humor may increase binding with adenylate cyclase-linked dopamine receptors in the ciliary body to alter fluid movement and potentially precipitate ciliochoroidal effusions [153].

Several antidepressants have been implicated in cases of AACC. Documented associations with AACC have been reported for amitriptyline [154], imipramine [149], venlafaxine [146-148], duloxetine [155], sertraline [156], paroxetine [143-145], fluoxetine [157], fluoxamine [158], citalopram [140, 141], and escitalopram [142, 149]. In a large population-based study using administrative data from an elderly Canadian population, Seitz et al. found that recent exposure to antidepressants was associated with increased risk of AACC; among this population there was a $62 \%$ increased odds for any antidepressant exposure in a 30-day period immediately preceding AACC [159]. The risk of AACC from SSRI use among a population with narrow iridocorneal angles appears to be even greater; in a large retrospective review of an ethnic Chinese population in Taiwan, Chen and colleagues found that patients taking SSRIs had nearly a six fold increased risk of developing AACC compared to non-users [160]. In addition, Chen's group found that this risk of angle closure increased to more than eight fold greater than nonusers among patients who were administered an average of $>20 \mathrm{mg}$ of SSRIs per day, suggesting a dose-dependent response. Given the overall safety profile and widespread use of SSRIs as first-line antidepressant therapy, primary care providers and mental health professionals who routinely prescribe these agents should alert patients about the risk of AACC and the need to seek eye care if AACC symptoms arise after initiating treatment.

\section{Adrenergics}

Adrenergic mydriasis occurs from overstimulation of the alpha-1-receptors of the iris dilator muscle, leading to sustained contraction, which can, in turn, lead to pupillary block in individuals with narrow angles. Reports of angle closure with use of oral, inhaled, and intranasal alpha adrenergic medications exist in the literature, including with the use of over-the-counter decongestants and commonly used anesthetic agents [134, 136, 137, 161-164]. Prone surgical positioning, use of analgesics, and use of anesthetic agents such as ephedrine are potential risk factors for AACC and delayed diagnosis of the condition [164].

\section{Cholinergics}

Pilocarpine is a cholinergic parasympathomimetic agent that acts through direct stimulation of muscarinic receptors and smooth muscle such as the iris and secretory glands. Pilocarpine is typically used to treat narrow angles by reducing iris thickness and iris-root pull to counteract forward displacement of the iris-lens diaphragm from ciliary muscle contraction. However, paradoxical acute angle closure following use of pilocarpine has been reported in patients with spherophakia, zonular weakness from exfoliation syndrome, phacomorphic glaucoma, and as well as in patients without any of these conditions [165].

\section{Anticoagulants}

Elderly patients taking anticoagulant and/or antiplatelet agents such as coumadin, heparin, and clopidogrel can, in rare cases, develop AACC from spontaneous suprachoroidal hemorrhage [166-170]. Abrupt forward displacement of the lens-iris diaphragm resulting from a massively detached choroid and retina is the proposed mechanism for causing these cases of AACC [168]. Increased age, systemic hypertension, atherosclerosis, age-related macular degeneration, nanophthalmos, prior vitrectomy, and chronic kidney diseases are risk factors in addition to iatrogenic anticoagluation [167, 169, 170]. In patients with age-related macular degeneration, a disciform macular lesion tends to be the source of hemorrhagic retinal or choroidal detachment; however, spontaneous choroidal hemorrhage and AACC has been reported in patients on anticoagulation without a choroidal neovascular membrane as the source of the bleed [169-172].

Topical aqueous suppressants and oral carbonic anhydrase inhibitors may be effective at lowering the IOP in these cases; however, treatment and prevention of recurrence may necessitate discontinuation of the anticoagulant if permitted by the patient's underlying medical condition [168, 171]. Evacuative sclerotomies may relieve pain and reduce IOP, but they have not been found to improve visual and anatomic outcomes [170].

\section{Conclusion}

Basic science research has demonstrated that various commonly used systemic medications can affect optic nerve perfusion, retinal ganglion cell survival, and aqueous humor outflow facility, suggesting these medications may modulate risk for OAG or disease progression. Over the past decade, a number these drugs have been found in large retrospective population-based studies to potentially modulate the risk of OAG, including metformin, statins, beta blockers, calcium channel blockers, SSRIs, bupropion, and postmenopausal hormones, although discordant findings exist in the literature, highlighting the need for welldesigned prospective randomized controlled trials to best examine the relationships between these systemic medications and risk for glaucoma.

Iatrogenic AACC is uncommon but can present bilaterally and may lead to profound visual morbidity if not 
recognized and treated in a timely manner. Most attacks of pupillary block occur among individuals with narrow iridocorneal angles who are unaware they are at higher risk of AACC. Prudent history taking in the primary care setting can identify individuals with risk factors for AACC such as hyperopia, personal or family history of glaucoma, or Asian ethnicity. Patients with these risk factors should be considered for referral for ophthalmologic evaluation prior to initiation of drugs with potential to induce AACC. Moreover, primary care physicians and health care professionals who routinely prescribe medications known to increase the risk of AACC should be familiar with this condition and alert patients to seek emergent care by an eye care professional if such symptoms develop soon after starting therapy with one of these medication classes. If recognized early, devastating visual consequences can be avoided by discontinuation of the offending agent and prompt reduction in IOP.

\section{Compliance with ethical standards}

Conflict of interest Dr. Pasquale is a consultant for Bausch + Lomb, Eyenovia, Nicox, and Verily.

Publisher's note Springer Nature remains neutral with regard to jurisdictional claims in published maps and institutional affiliations.

\section{References}

1. Flaxman SR, Bourne RRA, Resnikoff S, et al. Global causes of blindness and distance vision impairment 1990-2020: a systematic review and meta-analysis. Lancet Glob Health. 2017;5: e1221-e1234.

2. Tham YC, Li X, Wong TY, Quigley HA, Aung T, Cheng CY. Global prevalence of glaucoma and projections of glaucoma burden through 2040: a systematic review and meta-analysis. Ophthalmology. 2014;121:2081-90.

3. Foster PJ, Buhrmann R, Quigley HA, Johnson GJ. The definition and classification of glaucoma in prevalence surveys. $\mathrm{Br} \mathrm{J}$ Ophthalmol. 2002;86:238-42.

4. Kapetanakis VV, Chan MP, Foster PJ, Cook DG, Owen CG, Rudnicka AR. Global variations and time trends in the prevalence of primary open angle glaucoma (POAG): a systematic review and meta-analysis. Br J Ophthalmol. 2016;100:86-93.

5. Charlesworth CJ, Smit E, Lee DS, Alramadhan F, Odden MC. Polypharmacy among adults aged 65 years and older in the United States: 1988-2010. J Gerontol A Biol Sci Med Sci. 2015;70:989-95.

6. Kantor ED, Rehm CD, Haas JS, Chan AT, Giovannucci EL. Trends in prescription drug use among adults in the United States From 1999-2012. JAMA. 2015;314:1818-31.

7. Bernstein HN, Schwartz B. Effects of long-term systemic steroids on ocular pressure and tonographic values. Arch Ophthalmol. 1962;68:742-53.

8. Fini ME, Schwartz SG, Gao X, et al. Steroid-induced ocular hypertension/glaucoma: Focus on pharmacogenomics and implications for precision medicine. Prog Retin Eye Res. 2017;56:58-83.
9. Overby DR, Bertrand J, Tektas OY, et al. Ultrastructural changes associated with dexamethasone-induced ocular hypertension in mice. Investig Ophthalmol Vis Sci. 2014;55:4922-33.

10. Johnson D, Gottanka J, Flugel C, Hoffmann F, Futa R, LutjenDrecoll E. Ultrastructural changes in the trabecular meshwork of human eyes treated with corticosteroids. Arch Ophthalmol. 1997;115:375-83.

11. Johnson DH, Bradley JM, Acott TS. The effect of dexamethasone on glycosaminoglycans of human trabecular meshwork in perfusion organ culture. Investig Ophthalmol Vis Sci. 1990;31:2568-71.

12. Zhang X, Ognibene CM, Clark AF, Yorio T. Dexamethasone inhibition of trabecular meshwork cell phagocytosis and its modulation by glucocorticoid receptor beta. Exp Eye Res. 2007;84:275-84.

13. Kasetti RB, Maddineni P, Patel PD, Searby C, Sheffield VC, Zode GS. Transforming growth factorbeta2 (TGFbeta2) signaling plays a key role in glucocorticoid-induced ocular hypertension. J Biol Chem. 2018;293:9854-68.

14. Al Hanaineh AT, Hassanein DH, Abdelbaky SH, El Zawahry OM. Steroid-induced ocular hypertension in the pediatric age group. Eur J Ophthalmol. 2018;28:372-7.

15. Bartlett JD, Woolley TW, Adams CM. Identification of high intraocular pressure responders to topical ophthalmic corticosteroids. J Ocul Pharmacol. 1993;9:35-45.

16. Moss EB, Buys YM, Low SA, et al. A randomized controlled trial to determine the effect of inhaled corticosteroid on intraocular pressure in open-angle glaucoma and ocular hypertension: the ICOUGH study. J Glaucoma. 2017;26:182-6.

17. Tawara A, Tou N, Kubota T, Harada Y, Yokota K. Immunohistochemical evaluation of the extracellular matrix in trabecular meshwork in steroid-induced glaucoma. Graefes Arch Clin Exp Ophthalmol. 2008;246:1021-8.

18. Armaly MF. Effect of corticosteroids on intraocular pressure and fluid dynamics. I. The effect of dexamethasone in the normal eye. Arch Ophthalmol. 1963;70:482-91.

19. Armaly MF, Becker B. Intraocular pressure response to topical corticosteroids. Fed Proc. 1965;24:1274-8.

20. Tripathi RC, Tripathi BJ, Haggerty C. Drug-induced glaucomas: mechanism and management. Drug Saf. 2003;26:749-67.

21. Becker B. Intraocular pressure response to topical corticosteroids. Invest Ophthalmol. 1965;4:198-205.

22. Francois J. Corticosteroid glaucoma. Ann Ophthalmol. 1977;9:1075-80.

23. Tripathi RC, Parapuram SK, Tripathi BJ, Zhong Y, Chalam KV. Corticosteroids and glaucoma risk. Drugs Aging. 1999;15:439-50.

24. el-Harazi SM, Ruiz RS, Feldman RM, Villanueva G, Chuang AZ. A randomized double-masked trial comparing ketorolac tromethamine $0.5 \%$, diclofenac sodium $0.1 \%$, and prednisolone acetate $1 \%$ in reducing post-phacoemulsification flare and cells. Ophthalmic Surg Lasers. 1998;29:539-44.

25. Ngai P, Kim G, Chak G, Lin K, Maeda M, Mosaed S. Outcome of primary trabeculotomy ab interno (Trabectome) surgery in patients with steroid-induced glaucoma. Medicine. 2016;95: e5383.

26. Brusini P, Tosoni C, Zeppieri M. Canaloplasty in corticosteroidinduced glaucoma. Preliminary results. J Clin Med. 2018;7.

27. Bozkurt E, Kara N, Yazici AT, et al. Prophylactic selective laser trabeculoplasty in the prevention of intraocular pressure elevation after intravitreal triamcinolone acetonide injection. Am J Ophthalmol. 2011;152:976-81.e972.

28. Sousa DC, Leal I, Abegao Pinto L. Steroid-induced protracted severe ocular hypertension in a 14-year-old girl. BMJ Case Rep. 2018;2018:bcr-2018-225244. 
29. Waljee AK, Rogers MA, Lin P, et al. Short term use of oral corticosteroids and related harms among adults in the United States: population based cohort study. BMJ. 2017;357:j1415.

30. Phillips CI, Howitt G, Rowlands DJ. Propranolol as ocular hypotensive agent. Br J Ophthalmol. 1967;51:222-6.

31. Hohn R, Mirshahi A, Nickels S, et al. Cardiovascular medication and intraocular pressure: results from the Gutenberg Health Study. Br J Ophthalmol. 2017;101:1633-7.

32. Williamson J, Atta HR, Kennedy PA, Muir JG. Effect of orally administered nadolol on the intraocular pressure in normal volunteers. Br J Ophthalmol. 1985;69:38-40.

33. Elliot MJ, Cullen PM, Phillips CI. Ocular hypotensive effect of atenolol (Tenormin, I.C.I.). A new beta-adrenergic blocker. Br J Ophthalmol. 1975;59:296-300.

34. Khawaja AP, Chan MP, Broadway DC, et al. Systemic medication and intraocular pressure in a British population: the EPICNorfolk Eye Study. Ophthalmology. 2014;121:1501-7.

35. van der Valk R, Webers CA, Schouten JS, Zeegers MP, Hendrikse F, Prins MH. Intraocular pressure-lowering effects of all commonly used glaucoma drugs: a meta-analysis of randomized clinical trials. Ophthalmology. 2005;112:1177-85.

36. Muskens RP, de Voogd S, Wolfs RC, et al. Systemic antihypertensive medication and incident open-angle glaucoma. Ophthalmology. 2007;114:2221-6.

37. Schuman JS. Effects of systemic beta-blocker therapy on the efficacy and safety of topical brimonidine and timolol. Brimonidine Study Groups 1 and 2. Ophthalmology. 2000;107:1171-7.

38. Taniguchi T, Kitazawa Y. The potential systemic effect of topically applied beta-blockers in glaucoma therapy. Curr Opin Ophthalmol. 1997;8:55-8.

39. Lin HC, Stein JD, Nan B, et al. Association of geroprotective effects of metformin and risk of open-angle glaucoma in persons with diabetes mellitus. JAMA Ophthalmol. 2015;133:915-23.

40. Maleskic S, Kusturica J, Gusic E, et al. Metformin use associated with protective effects for ocular complications in patients with type 2 diabetes-observational study. Acta Med Acad. 2017;46:116-23.

41. Rosen P, Wiernsperger NF. Metformin delays the manifestation of diabetes and vascular dysfunction in Goto-Kakizaki rats by reduction of mitochondrial oxidative stress. Diabetes Metab Res Rev. 2006;22:323-30.

42. Wang SV, Li N, Rice DS, et al. Using healthcare databases to refine understanding of exploratory associations between drugs and progression of open angle glaucoma. Clin Pharm Ther. 2019;106:874-83.

43. Zacco A, Togo J, Spence K, et al. 3-hydroxy-3-methylglutaryl coenzyme A reductase inhibitors protect cortical neurons from excitotoxicity. J Neurosci. 2003;23:11104-11.

44. Honjo M, Tanihara $\mathrm{H}$, Nishijima $\mathrm{K}$, et al. Statin inhibits leukocyte-endothelial interaction and prevents neuronal death induced by ischemia-reperfusion injury in the rat retina. Arch Ophthalmol. 2002;120:1707-13.

45. Kim ML, Sung KR, Shin JA, Young Yoon J, Jang J. Statins reduce TGF-beta2-modulation of the extracellular matrix in cultured astrocytes of the human optic nerve head. Exp Eye Res. 2017;164:55-63.

46. McGwin G, Jr., McNeal S, Owsley C, Girkin C, Epstein D. Statins and other cholesterol-lowering medications and the presence of glaucoma. Arch Ophthalmol. 2004;122:822-6.

47. Nagaoka T, Takahashi A, Sato E, et al. Effect of systemic administration of simvastatin on retinal circulation. Arch Ophthalmol. 2006; 124:665-70.

48. Rikitake Y, Liao JK. Rho GTPases, statins, and nitric oxide. Circ Res. 2005;97:1232-5.
49. Rao PV, Deng PF, Kumar J, Epstein DL. Modulation of aqueous humor outflow facility by the Rho kinase-specific inhibitor Y27632. Investig Ophthalmol Vis Sci. 2001;42:1029-37.

50. Bosel J, Gandor F, Harms C, et al. Neuroprotective effects of atorvastatin against glutamate-induced excitotoxicity in primary cortical neurones. J Neurochem. 2005;92:1386-98.

51. Talwar N, Musch DC, Stein JD. Association of daily dosage and type of statin agent with risk of open-angle glaucoma. JAMA Ophthalmol. 2017;135:263-7.

52. Stein JD, Newman-Casey PA, Talwar N, Nan B, Richards JE, Musch DC. The relationship between statin use and open-angle glaucoma. Ophthalmology. 2012;119:2074-81.

53. Marcus MW, Muskens RP, Ramdas WD, et al. Cholesterollowering drugs and incident open-angle glaucoma: a populationbased cohort study. PLoS ONE. 2012;7:e29724.

54. Kang JH, Boumenna T, Stein JD, et al. Association of Statin use and high serum cholesterol levels with risk of primary openangle glaucoma. JAMA Ophthalmol. 2019;137:756-65.

55. Whigham B, Oddone EZ, Woolson S, et al. The influence of oral statin medications on progression of glaucomatous visual field loss: a propensity score analysis. Ophthalmic Epidemiol. 2018;25:207-14.

56. Leung DY, Li FC, Kwong YY, Tham CC, Chi SC, Lam DS. Simvastatin and disease stabilization in normal tension glaucoma: a cohort study. Ophthalmology. 2010;117:471-6.

57. De Castro DK, Punjabi OS, Bostrom AG, et al. Effect of statin drugs and aspirin on progression in open-angle glaucoma suspects using confocal scanning laser ophthalmoscopy. Clin Exp Ophthalmol. 2007;35:506-13.

58. Chen HY, Hsu SY, Chang YC, et al. Association between statin use and open-angle glaucoma in hyperlipidemia patients: a Taiwanese population-based case-control study. Medicine. 2015;94:e2018.

59. Ho H, Shi Y, Chua J, et al. Association of systemic medication use with intraocular pressure in a multiethnic Asian population: the Singapore Epidemiology of Eye Diseases Study. JAMA Ophthalmol. 2017;135:196-202.

60. Iskedjian M, Walker JH, Desjardins O, et al. Effect of selected antihypertensives, antidiabetics, statins and diuretics on adjunctive medical treatment of glaucoma: a population based study. Curr Med Res Opin. 2009;25:1879-88.

61. Aguilar M, Bhuket T, Torres S, Liu B, Wong RJ. Prevalence of the metabolic syndrome in the United States, 2003-212. JAMA. 2015;313:1973-4.

62. Newman-Casey PA, Talwar N, Nan B, Musch DC, Stein JD. The relationship between components of metabolic syndrome and open-angle glaucoma. Ophthalmology. 2011;118:1318-26.

63. Zheng W, Dryja TP, Wei Z, et al. Systemic medication associations with presumed advanced or uncontrolled primary openangle glaucoma. Ophthalmology. 2018;125:984-93.

64. Costagliola C, Parmeggiani F, Sebastiani A. SSRIs and intraocular pressure modifications: evidence, therapeutic implications and possible mechanisms. CNS Drugs. 2004;18:475-84.

65. Stein JD, Talwar N, Kang JH, Okereke OI, Wiggs JL, Pasquale LR. Bupropion use and risk of open-angle glaucoma among enrollees in a large U.S. managed care network. PLoS ONE. 2015;10:e0123682.

66. Masis M, Kakigi C, Singh K, Lin S. Association between selfreported bupropion use and glaucoma: a population-based study. Br J Ophthalmol. 2017;101:525-9.

67. Tezel G, Li LY, Patil RV, Wax MBTNF-alpha. and TNF-alpha receptor-1 in the retina of normal and glaucomatous eyes. Investig Ophthalmol Vis Sci. 2001;42:1787-94.

68. Roh M, Zhang Y, Murakami Y, et al. Etanercept, a widely used inhibitor of tumor necrosis factor-alpha (TNF-alpha), prevents 
retinal ganglion cell loss in a rat model of glaucoma. PLoS ONE. 2012;7:e40065.

69. Lee AJ, Mitchell P, Rochtchina E, Healey PR. Female reproductive factors and open angle glaucoma: the Blue Mountains Eye Study. Br J Ophthalmol. 2003;87:1324-8.

70. Hulsman CA, Westendorp IC, Ramrattan RS, et al. Is open-angle glaucoma associated with early menopause? The Rotterdam Study. Am J Epidemiol. 2001;154:138-44.

71. Newman-Casey PA, Talwar N, Nan B, Musch DC, Pasquale LR, Stein JD. The potential association between postmenopausal hormone use and primary open-angle glaucoma. JAMA Ophthalmol. 2014;132:298-303.

72. Vajaranant TS, Ray RM, Pasquale LR, et al. Racial differences in the effects of hormone therapy on incident open-angle glaucoma in a randomized trial. Am J Ophthalmol. 2018;195:110-20.

73. Tint NL, Alexander P, Tint KM, Vasileiadis GT, Yeung AM, Azuara-Blanco A. Hormone therapy and intraocular pressure in nonglaucomatous eyes. Menopause. 2010;17:157-60.

74. Uncu G, Avci R, Uncu Y, Kaymaz C, Develioglu O. The effects of different hormone replacement therapy regimens on tear function, intraocular pressure and lens opacity. Gynecol Endocrinol. 2006;22:501-5.

75. Vajaranant TS, Maki PM, Pasquale LR, Lee A, Kim H, Haan MN. Effects of hormone therapy on intraocular pressure: The Women's Health Initiative-Sight Exam Study. Am J Ophthalmol. 2016;165:115-24.

76. Pasquale LR, Kang JH. Female reproductive factors and primary open-angle glaucoma in the Nurses' Health Study. Eye. 2011;25:633-41.

77. Pasquale LR, Rosner BA, Hankinson SE, Kang JH. Attributes of female reproductive aging and their relation to primary open-angle glaucoma: a prospective study. J Glaucoma. 2007;16:598-605.

78. Doshi V, et al. Los Angeles Latino Eye Study Group. Sociodemographic, family history, and lifestyle risk factors for openangle glaucoma and ocular hypertension. The Los Angeles Latino Eye Study. Ophthalmology. 2008;115:639-47.e2.

79. Kang JH, et al. Endothelial nitric oxide synthase gene variants and primary open-angle glaucoma: interactions with sex and postmenopausal hormone use. Invest Ophthalmol Vis Sci. 2010;51:971-9.

80. Affinito P, Di Spiezio Sardo A, Di Carlo C, et al. Effects of hormone replacement therapy on ocular function in postmenopause. Menopause. 2003;10:482-7.

81. Altintas O, Caglar Y, Yuksel N, Demirci A, Karabas L. The effects of menopause and hormone replacement therapy on quality and quantity of tear, intraocular pressure and ocular blood flow. Ophthalmologica. 2004;218:120-9.

82. Coksuer H, Ozcura F, Oghan F, Haliloglu B, Coksuer C. Effects of estradiol-drospirenone on ocular and nasal functions in postmenopausal women. Climacteric. 2011;14:482-7.

83. Sator MO, Joura EA, Frigo $\mathrm{P}$, et al. Hormone replacement therapy and intraocular pressure. Maturitas. 1997;28:55-8.

84. Treister G, Mannor S. Intraocular pressure and outflow facility. Effect of estrogen and combined estrogen-progestin treatment in normal human eyes. Arch Ophthalmol. 1970;83:311-8.

85. Abramov Y, Borik S, Yahalom C, et al. Does postmenopausal hormone replacement therapy affect intraocular pressure? J Glaucoma. 2005;14:271-5.

86. Guaschino S, Grimaldi E, Sartore A, et al. Visual function in menopause: the role of hormone replacement therapy. Menopause. 2003;10:53-7.

87. Toker E, Yenice O, Temel A. Influence of serum levels of sex hormones on intraocular pressure in menopausal women. J Glaucoma. 2003;12:436-40.
88. Chen X, Liu Y, Zhang Y, Kam WR, Pasquale LR, Sullivan DA. Impact of aromatase absence on murine intraocular pressure and retinal ganglion cells. Sci Rep. 2018;8:3280.

89. Straiker AJ, Maguire G, Mackie K, Lindsey J. Localization of cannabinoid CB1 receptors in the human anterior eye and retina. Investig Ophthalmol Vis Sci. 1999;40:2442-8.

90. Tiedeman JS, Shields MB, Weber PA, et al. Effect of synthetic cannabinoids on elevated intraocular pressure. Ophthalmology. 1981;88:270-7.

91. Novack GD. Cannabinoids for treatment of glaucoma. Curr Opin Ophthalmol. 2016;27:146-50.

92. Zhan GL, Camras CB, Palmberg PF, Toris CB. Effects of marijuana on aqueous humor dynamics in a glaucoma patient. $\mathrm{J}$ Glaucoma. 2005;14:175-7.

93. Buys YM, Rafuse PE. Canadian Ophthalmological Society policy statement on the medical use of marijuana for glaucoma. Can J Ophthalmol. 2010;45:324-6. England.

94. Jampel H. American glaucoma society position statement: marijuana and the treatment of glaucoma. $\mathrm{J}$ Glaucoma. 2010;19:75-76. United States.

95. Tomita K, Araie M, Tamaki Y, Nagahara M, Sugiyama T. Effects of nilvadipine, a calcium antagonist, on rabbit ocular circulation and optic nerve head circulation in NTG subjects. Investig Ophthalmol Vis Sci. 1999;40:1144-51.

96. Luksch A, Rainer G, Koyuncu D, et al. Effect of nimodipine on ocular blood flow and colour contrast sensitivity in patients with normal tension glaucoma. $\mathrm{Br} \mathrm{J}$ Ophthalmol. 2005;89:21-5.

97. Koseki N, Araie M, Yamagami J, Shirato S, Yamamoto S. Effects of oral brovincamine on visual field damage in patients with normal-tension glaucoma with low-normal intraocular pressure. J Glaucoma. 1999;8:117-23.

98. Netland PA, Chaturvedi N, Dreyer EB. Calcium channel blockers in the management of low-tension and open-angle glaucoma. Am J Ophthalmol. 1993;115:608-13.

99. Quill B, Irnaten M, Docherty NG, et al. Calcium channel blockade reduces mechanical strain-induced extracellular matrix gene response in lamina cribrosa cells. $\mathrm{Br} \mathrm{J}$ Ophthalmol. 2015;99:1009-14.

100. Tamaki Y, Araie M, Fukaya Y, et al. Effects of lomerizine, a calcium channel antagonist, on retinal and optic nerve head circulation in rabbits and humans. Investig Ophthalmol Vis Sci. 2003;44:4864-71.

101. Acelajado MC, Hughes ZH, Oparil S, Calhoun DA. Treatment of Resistant and Refractory Hypertension. Circ Res. 2019;124:1061-70.

102. Korol EA. Transitory myopia in combination with transitory glaucoma. Zdravookhr Beloruss. 1962;8:66-7.

103. Rapoport Y, Benegas N, Kuchtey RW, Joos KM. Acute myopia and angle closure glaucoma from topiramate in a seven-year-old: a case report and review of the literature. BMC Pediatr. 2014; $14: 96$

104. Lan YW, Hsieh JW. Bilateral acute angle closure glaucoma and myopic shift by topiramate-induced ciliochoroidal effusion: case report and literature review. Int Ophthalmol. 2018;38:2639-48.

105. Rhee DJ, Goldberg MJ, Parrish RK. Bilateral angle-closure glaucoma and ciliary body swelling from topiramate. Arch Ophthalmol. 2001;119:1721-3.

106. Ikeda N, Ikeda T, Nagata M, Mimura O. Ciliochoroidal effusion syndrome induced by sulfa derivatives. Arch Ophthalmol. 2002;120:1775. United States

107. Czyz CN, Clark CM, Justice JD, Pokabla MJ, Weber PA. Delayed topiramate-induced bilateral angle-closure glaucoma. J Glaucoma. 2014;23:577-8. 
108. Kozner P, Simonova K, Brozek B, Singh K. Late acute myopia syndrome induced by combination of sulfonamide drugs. $\mathrm{J}$ Glaucoma. 2014;23:e119-121.

109. Caglar C, Yasar T, Ceyhan D. Topiramate induced bilateral angle-closure glaucoma: low dosage in a short time. J Ocul Pharm Ther. 2012;28:205-7.

110. Kamal S, Yadava U, Kumar S, Goel R. Topiramate-induced angle-closure glaucoma: cross-sensitivity with other sulphonamide derivatives causing anterior uveitis. Int Ophthalmol. 2014;34:345-9.

111. Saffra N, Smith SN, Seidman CJ. Topiramate-induced refractive change and angle closure glaucoma and its ultrasound bimicroscopy findings. BMJ Case Rep. 2012;2012 bcr2012006509.

112. Sankar PS, Pasquale LR, Grosskreutz CL. Uveal effusion and secondary angle-closure glaucoma associated with topiramate use. Arch Ophthalmol. 2001;119:1210-1.

113. Malagola R, Arrico L, Giannotti R, Pattavina L. Acetazolamideinduced cilio-choroidal effusion after cataract surgery: unusual posterior involvement. Drug Des Devel Ther. 2013;7:33-6.

114. Parthasarathi S, Myint K, Singh G, Mon S, Sadasivam P, Dhillon B. Bilateral acetazolamide-induced choroidal effusion following cataract surgery. Eye. 2007;21:870-2. England

115. Lee GC, Tam CP, Danesh-Meyer HV, Myers JS, Katz LJ. Bilateral angle closure glaucoma induced by sulphonamidederived medications. Clin Exp Ophthalmol. 2007;35:55-8.

116. Aref AA, Sayyad FE, Ayres B, Lee RK. Acute bilateral angle closure glaucoma induced by methazolamide. Clin Ophthalmol. 2013;7:279-82. New Zealand

117. Kwon SJ, Park DH, Shin JP. Bilateral transient myopia, angleclosure glaucoma, and choroidal detachment induced by methazolamide. Jpn J Ophthalmol. 2012;56:515-7.

118. Murphy RM, Bakir B, O'Brien C, Wiggs JL, Pasquale LR. Druginduced bilateral secondary angle-closure glaucoma: a literature synthesis. J Glaucoma. 2016;25:e99-105.

119. Boundaoui ON, Woodruff TE. Presumed furosemide-associated bilateral angle-closure glaucoma. J Glaucoma. 2016;25: e748-750.

120. Weiler DL. Zonisamide-induced angle closure and myopic shift. Optom Vis Sci. 2015;92:e46-51.

121. Sen HA, O'Halloran HS, Lee WB. Case reports and small case series: topiramate-induced acute myopia and retinal striae. Arch Ophthalmol. 2001;119:775-7.

122. Craig JE, Ong TJ, Louis DL, Wells JM. Mechanism of topiramate-induced acute-onset myopia and angle closure glaucoma. Am J Ophthalmol. 2004;137:193-5.

123. Symes RJ, Etminan M, Mikelberg FS. Risk of angle-closure glaucoma with bupropion and topiramate. JAMA Ophthalmol. 2015;133:1187-9.

124. Fraunfelder FW, Fraunfelder FT, Keates EU. Topiramateassociated acute, bilateral, secondary angle-closure glaucoma. Ophthalmology. 2004;111:109-11.

125. Mancino R, Varesi C, Cerulli A, Aiello F, Nucci C. Acute bilateral angle-closure glaucoma and choroidal effusion associated with acetazolamide administration after cataract surgery. $\mathbf{J}$ Cataract Refract Surg. 2011;37:415-7.

126. Parikh R, Parikh S, Das S, Thomas R. Choroidal drainage in the management of acute angle closure after topiramate toxicity. $\mathrm{J}$ Glaucoma. 2007;16:691-3.

127. Patel KH, Javitt JC, Tielsch JM, et al. Incidence of acute angleclosure glaucoma after pharmacologic mydriasis. Am J Ophthalmol. 1995;120:709-17.

128. Wolfs RC, Grobbee DE, Hofman A, de Jong PT. Risk of acute angle-closure glaucoma after diagnostic mydriasis in nonselected subjects: the Rotterdam Study. Investig Ophthalmol Vis Sci. 1997;38:2683-7.
129. Jain D, Dhua A, Ravisankar V, Chellam L, Joshi M. Acute angle closure glaucoma after hypospadias surgery: A visionthreatening complication of oxybutynin. J Indian Assoc Pediatr Surg. 2015;20:161-2.

130. Haddad A, Arwani M, Sabbagh O. A novel association between oxybutynin use and bilateral acute angle closure glaucoma: a case report and literature review. Cureus. 2018;10:e2732.

131. Rudkin AK, Gray TL, Awadalla M, Craig JE. Bilateral simultaneous acute angle closure glaucoma precipitated by nonprescription cold and flu medication. Emerg Med Australas. 2010;22:477-9.

132. Lentschener C, Ghimouz A, Bonnichon P, Parc C, Ozier Y. Acute postoperative glaucoma after nonocular surgery remains a diagnostic challenge. Anesth Analg. 2002;94:1034-5. table of contents

133. Raj KM, Reddy PA, Kumar VC. Bilateral angle closure glaucoma following general anaesthesia. J Pharm Bioallied Sci. 2015;7:S70-71. India

134. Lotery AJ, Frazer DG. Iatrogenic acute angle closure glaucoma masked by general anaesthesia and intensive care. Ulst Med J. 1995;64:178-80.

135. Oksuz H, Tamer C, Akoglu S, Duru M. Acute angle-closure glaucoma precipitated by local tiotropium absorption. Pulm Pharm Ther. 2007;20:627-8.

136. Reuser T, Flanagan DW, Borland C, Bannerjee DK. Acute angle closure glaucoma occurring after nebulized bronchodilator treatment with ipratropium bromide and salbutamol. J R Soc Med. 1992;85:499-500.

137. Hall SK. Acute angle-closure glaucoma as a complication of combined beta-agonist and ipratropium bromide therapy in the emergency department. Ann Emerg Med. 1994;23:884-7.

138. Corridan P, Nightingale S, Mashoudi N, Williams AC. Acute angle-closure glaucoma following botulinum toxin injection for blepharospasm. Br J Ophthalmol. 1990;74:309-10.

139. Tsai JC. Acute angle closure following periorbital botulinum toxin injection in a patient with retinitis pigmentosa. Taiwan $\mathrm{J}$ Ophthalmol. 2017;7:104-7. India

140. Massaoutis P, Goh D, Foster PJ. Bilateral symptomatic angle closure associated with a regular dose of citalopram, an SSRI antidepressant. Br J Ophthalmol. 2007;91:1086-7. England

141. Croos R, Thirumalai S, Hassan S, Davis Jda R. Citalopram associated with acute angle-closure glaucoma: case report. BMC Ophthalmol. 2005;5:23.

142. Zelefsky JR, Fine HF, Rubinstein VJ, Hsu IS, Finger PT. Escitalopram-induced uveal effusions and bilateral angle closure glaucoma. Am J Ophthalmol. 2006;141:1144-7.

143. Sierra-Rodriguez MA, Saenz-Frances F, Santos-Bueso E, Garcia-Feijoo J, Gonzelez-Romero JC. Chronic angle-closure glaucoma related to paroxetine treatment. Semin Ophthalmol. 2013;28:244-6.

144. Levy J, Tessler Z, Klemperer I, Shneck M, Lifshitz T. Late bilateral acute angle-closure glaucoma after administration of paroxetine in a patient with plateau iris configuration. Can J Ophthalmol. 2004;39:780-1.

145. Bennett HG, Wyllie AM. Paroxetine and acute angle-closure glaucoma. Eye. 1999;13(Pt 5):691-2.

146. Zhou N, Zhao JX, Zhu YN, Zhang P, Zuo Y. Acute angleclosure glaucoma caused by venlafaxine. Chin Med J. 2018;131:1502-3. China

147. de Guzman MH, Thiagalingam S, Ong PY, Goldberg I. Bilateral acute angle closure caused by supraciliary effusions associated with venlafaxine intake. Med J Aust. 2005;182:121-3.

148. Aragona $M$, Inghilleri $M$. Increased ocular pressure in two patients with narrow angle glaucoma treated with venlafaxine. Clin Neuropharmacol. 1998;21:130-1. 
149. Ritch R, Krupin T, Henry C, Kurata F. Oral imipramine and acute angle closure glaucoma. Arch Ophthalmol. 1994;112:67-8.

150. Postel EA, Assalian A, Epstein DL. Drug-induced transient myopia and angle-closure glaucoma associated with supraciliary choroidal effusion. Am J Ophthalmol. 1996;122:110-2.

151. Barnett NL, Osborne NN. The presence of serotonin (5-HT1) receptors negatively coupled to adenylate cyclase in rabbit and human iris-ciliary processes. Exp Eye Res. 1993;57:209-16.

152. Martin XD, Brennan MC, Lichter PR. Serotonin in human aqueous humor. Ophthalmology. 1988;95:1221-6.

153. De Vries GW, Mobasser A, Wheeler LA. Stimulation of endogenous cyclic AMP levels in ciliary body by SK\&F 82526, a novel dopamine receptor agonist. Curr Eye Res. 1986;5:449-55.

154. Lowe RF. Amitriptyline and glaucoma. Med J Aust. 1966;2:509-10.

155. Shifera AS, Leoncavallo A, Sherwood M. Probable association of an attack of bilateral acute angle-closure glaucoma with duloxetine. Ann Pharmacother. 2014;48:936-9.

156. Ho HY, Kam KW, Young AL, Chan LK, Yu EC. Acute angle closure glaucoma after sertraline. Gen Hosp Psychiatry. 2013;35:575.e571-572.

157. Ahmad S. Fluoxetine and glaucoma. Dicp. 1991;25:436.

158. Jimenez-Jimenez FJ, Orti-Pareja M, Zurdo JM. Aggravation of glaucoma with fluvoxamine. Ann Pharmacother. 2001;35:1565-6.

159. Seitz DP, Campbell RJ, Bell CM, et al. Short-term exposure to antidepressant drugs and risk of acute angle-closure glaucoma among older adults. J Clin Psychopharmacol. 2012;32:403-7.

160. Chen HY, Lin CL, Lai SW, Kao CH. Association of selective serotonin reuptake inhibitor use and acute angle-closure glaucoma. J Clin Psychiatry. 2016;77:e692-696.

161. Zenzen CT, Eliott D, Balok EM, Watnick RL, German P. Acute angle-closure glaucoma associated with intranasal phenylephrine to treat epistaxis. Arch Ophthalmol. 2004;122:655-6.

162. Khan MA, Watt LL, Hugkulstone CE. Bilateral acute angleclosure glaucoma after use of Fenox nasal drops. Eye. 2002;16:662-3.
163. Nicoara SD, Damian I. Bilateral simultaneous acute angle closure attack triggered by an over-the-counter flu medication. Int Ophthalmol. 2018;38:1775-8.

164. Gayat E, Gabison E, Devys JM. Case report: bilateral angle closure glaucoma after general anesthesia. Anesth Analg. 2011;112:126-8.

165. Day AC, Nolan W, Malik AN, Viswanathan AC, Foster PJ. Pilocarpine induced acute angle closure. BMJ Case Rep. 2012;2012:bcr0120125694.

166. Schlote T, Freudenthaler N, Gelisken F. Anticoagulative therapy in patients with exudative age-related macular degeneration: acute angle closure glaucoma after massive intraocular hemorrhage. Ophthalmologe. 2005;102:1090-6.

167. Caronia RM, Sturm RT, Fastenberg DM, Berke SJ, Weintraub J. Bilateral secondary angle-closure glaucoma as a complication of anticoagulation in a nanophthalmic patient. Am J Ophthalmol. 1998;126:307-9.

168. Neudorfer M, Leibovitch I, Goldstein M, Loewenstein A. Massive choroidal hemorrhage associated with low molecular weight heparin therapy. Blood Coagul Fibrinolysis. 2002;13:257-9.

169. Masri I, Smith JM, Wride NK, Ghosh S. A rare case of acute angle closure due to spontaneous suprachoroidal haemorrhage secondary to loss of anti-coagulation control: a case report. BMC Ophthalmol. 2018;18(Suppl 1):224.

170. De Marco R, Aurilia P, Mele A. Massive spontaneous choroidal hemorrhage in a patient with chronic renal failure and coronary artery disease treated with Plavix. Eur J Ophthalmol. 2009;19:883-6.

171. Pesin SR, Katz LJ, Augsburger JJ, Chien AM, Eagle RC Jr. Acute angle-closure glaucoma from spontaneous massive hemorrhagic retinal or choroidal detachment. An updated diagnostic and therapeutic approach. Ophthalmology. 1990;97:76-84.

172. Lee YJ, Kang SM, Kang IB. Acute angle-closure glaucoma from spontaneous massive hemorrhagic retinal detachment. Korean J Ophthalmol. 2007;21:61-4. 